\title{
Cardiovascular responses to sugary drinks in humans: galactose presents milder cardiac effects than glucose or fructose
}

\author{
Nathalie Charrière $^{1} \cdot$ Cathriona Loonam $^{1} \cdot$ Jean-Pierre Montani $^{1} \cdot$ Abdul G. Dulloo $^{1}$ \\ Erik K. Grasser ${ }^{1}$
}

\begin{abstract}
Purpose There is increasing interest into the potentially beneficial effects of galactose for obesity and type 2 diabetes management as it is a low-glycemic sugar reported to increase satiety and fat mobilization. However, fructose is also a low-glycemic sugar but with greater blood pressure elevation effects than after glucose ingestion. Therefore, we investigated here the extent to which the ingestion of galactose, compared to glucose and fructose, impacts upon haemodynamics and blood pressure.

Methods In a randomized cross-over study design, 9 overnight-fasted young men attended 3 separate morning sessions during which continuous cardiovascular monitoring was performed at rest for at least $30 \mathrm{~min}$ before and $120 \mathrm{~min}$ after ingestion of $500 \mathrm{~mL}$ of water containing $60 \mathrm{~g}$ of either glucose, fructose or galactose. These measurements included beat-to-beat systolic and diastolic blood pressure, heart rate deduced by electrocardiography, and stroke volume derived by impedance cardiography; these measurements were used to calculate cardiac output and total peripheral resistance.

Results Ingestion of galactose, like glucose, led to significantly lesser increases in systolic, diastolic and mean blood pressure than fructose ingestion $(p<0.05)$. Furthermore, the increase in cardiac output and reduction in total peripheral resistance observed after ingestion of glucose were markedly lower after galactose ingestion $(p<0.01)$.
\end{abstract}

Erik K. Grasser

erikkonrad.grasser@unifr.ch

1 Laboratory of Integrative Cardiovascular and Metabolic Physiology, Division of Physiology, Department of Medicine, University of Fribourg, 1700 Fribourg, Switzerland
Conclusions Galactose thus presents the interesting characteristics of a low-glycemic sugar with mild cardiovascular effects. Further studies are warranted to confirm the clinical relevance of the milder cardiovascular effects of galactose than other sugars for insulin resistant obese and/ or diabetic patients with cardiac insufficiency.

Keywords Sucrose $\cdot$ Beat-to-beat $\cdot$ Randomized controlled trial $\cdot$ Cardiac effects $\cdot$ Clinical implication

\section{Introduction}

A rise in the consumption of refined sugars in food and beverages has often been implicated in the epidemic of obesity, type 2 diabetes and cardiovascular diseases. While most added sugars are consumed as the disaccharide sucrose or in the form of its two constituent monosaccharides (glucose and fructose), it is its fructose moiety which, despite its classification as a low-glycemic sugar, is viewed as the more harmful sugar component [1].

Indeed, chronic studies comparing diets containing fructose in substitution for glucose have demonstrated a more adverse lipid profile and greater cardiometabolic risks [1, 2].

During the past decade, there has been increasing interest in the potential beneficial effects of galactose [3-10], a low-glycemic sugar monosaccharide which in combination with glucose constitutes the disaccharide lactose. Although galactose is absorbed at the same rate as glucose, most of it is taken up by the liver where it is metabolized to other substrates (glucose, lactate or fatty acids) that are readily metabolized by extrahepatic cells [11]. Consequently, as the release of galactose in the form of glucose into the blood is delayed, it could provide an energy source of choice with 
a low-glycemic index and a low-insulinemic response [1215]. Indeed, several studies in healthy humans have shown that the ingestion of galactose elicits only small increases in plasma glucose and insulin, which are not different from those in response to fructose ingestion [12-15].

This specific metabolic fate of galactose has formed the basis of interest in this low-glycemic sugar with respect to its potential impact on exercise performance $[5,8,10]$ and more recently for weight control $[3,4,6,7,9,10]$. In the latter context, several acute studies have shown that ingestion of galactose leads to increased satiety [3, 4, 10]. Furthermore, a chronic study involving intermittent intake of sugary drinks in women has shown that intake of galactose in substitution for glucose resulted in increased fat mobilization and oxidation [6], which would be consistent with the much lesser impact of galactose than glucose ingestion on circulating insulin [12-15]. These studies have led to the proposal that diets with galactose as a source of carbohydrates could be useful in the management of obesity and type 2 diabetes.

Little is known, however, about the impact of galactose ingestion on the cardiovascular system. By contrast, it has repeatedly been demonstrated that the ingestion of glucose and fructose drinks is characterized by specific haemodynamic responses in healthy young $[16,17]$ and older people [18]. Unlike drinking glucose, which decreases total peripheral resistance by an insulin-mediated release of nitric oxide accompanied by a metabolic vasodilation leading to an increase in cardiac output (CO), thereby resulting in little or no change in blood pressure (BP), the ingestion of fructose elicits a significant increase in $\mathrm{BP}$ that results from a more modest increase in CO but without a decrease in TPR [16, 17]. These differential BP responses to glucose and fructose ingestion have been attributed to their differential effects on insulin secretion [17], and to the well-known effect of insulin not only in enhancing sympathetic activation of cardiac contractility (hence contributing to the increased CO) [19], but also in stimulating peripheral vasodilatation and hence decreasing TPR [20]. In this context, the question arises as to whether ingestion of galactose, which like fructose has only a mild stimulatory effect on insulin release [12-15], would also lead to higher BP. In testing this hypothesis, the aim of our study here was to investigate, using comprehensive and continuous cardiovascular monitoring, potential differences in BP and haemodynamics between galactose, glucose and fructose in a cross-over study design in young men.

\section{Methods}

\section{Subjects}

Nine healthy young men aged $24 \pm 1$ year (mean \pm SD) were recruited from local students and their friends. The mean height of the participants was $182 \pm 7 \mathrm{~cm}$, body weight was $79 \pm 13 \mathrm{~kg}$ and BMI was $23.8 \pm 2.8 \mathrm{~kg} /$ $\mathrm{m}^{2}$. Before their first test, subjects had to fill out a questionnaire about their health and lifestyle and underwent BP and anthropometric measurements to ensure a healthy condition. We defined healthy on the basis that all of our test subjects were non-obese with normal resting BP (brachial systolic/diastolic BP $<140 / 90 \mathrm{mmHg}$ and $>100 \mathrm{mmHg}$ systolic BP) and none of our subjects had any diseases or were taking any medication affecting cardiovascular regulation. All participants fasted for $\geq 12 \mathrm{~h}$ and abstained from alcohol, smoking and caffeine as well as from vigorous exercise for $24 \mathrm{~h}$ prior to each test and were advised not to change their dietary habits between the tests. This study was conducted according to the guidelines laid down in the Declaration of Helsinki, all procedures involving human subjects were approved by the Cantonal Ethics Committee, and written informed consent was obtained from all subjects prior to their inclusion in the study.

\section{Experimental design}

All studies started between 08:00 and 09:00 in a quiet, air-conditioned laboratory $\left(21{ }^{\circ} \mathrm{C}\right)$, with the subjects at thermal comfort. Every test subject attended three separate experimental sessions (separated by at least 2 days) according to a randomized cross-over design. Randomization was performed using a random sequence generator (https://www.randomizer.org/) where the sessions order was determined for 9 test subjects before the study started. At each experimental session, the cardiovascular responses to one of three drinks were monitored. The drinks tested were as follows: (1) water containing $60 \mathrm{~g}$ of $\mathrm{D}(+)$-glucose, (2) water containing $60 \mathrm{~g}$ of $\mathrm{D}(+)$ galactose, and (3) water containing $60 \mathrm{~g} \mathrm{D}(-)$-fructose. The purity of all sugars was $99 \%$ (Argos Organics, Chemie Brunschwig SA, Basel, Switzerland). Each drink also contained $10 \mathrm{~mL}$ lemon juice (to mask the difference in sweetness) and was made up to a total of $500 \mathrm{~mL}$ by addition of distilled water $\left(21^{\circ} \mathrm{C}\right)$. The subjects were not told the order of the drinks.

On arrival at the laboratory, subjects were asked to empty their bladders if necessary and to sit in a comfortable armchair. After waiting for a 20-30 min period to attain cardiovascular stability, continuous beat-bybeat recordings were initiated starting with at least a 30-min baseline period after which the subject ingested the respective test drink over a period of $4 \mathrm{~min}$, which was followed by post-drink cardiovascular recordings over the next $120 \mathrm{~min}$. The subjects were allowed to watch documentaries and calm movies in order to reduce boredom. 


\section{Haemodynamics}

A Task Force Monitor (CNSystems, Medizintechnik, Graz, Austria) was used to perform cardiovascular recordings, and data were sampled at a rate of $1000 \mathrm{~Hz}$ [21]. Continuous BP was monitored using the Penaz principle from either the index or middle finger (automatically finger switch every $30 \mathrm{~min}$ ) of the right hand and was calibrated to oscillometric brachial BP measurements on the contralateral arm. The right hand with the continuous BP cuff rested on a ductile pillow which was positioned at heart level on a height adjustable table. Impedance cardiography measurements [22], in which the changes in thoracic impedance are converted to reflect changes in thoracic fluid content/volume over time, were taken based on the original Kubicek [23] approach, but using an improved estimate of thoracic volume [24], which allows calculation of cardiac stroke volume (SV). ECG/impedance electrodes were positioned together with upper arm and finger BP cuffs. Electrode strips were placed at the neck and thoracic regions, the latter specifically at the midclavicular at the xiphoid process level (CNSystems standard electrode kits).

\section{Statistical analysis}

Values of cardiac interval, systolic BP (SBP), diastolic BP (DBP) and SV were averaged every 20 min during the baseline period and the 120 min post-drink period. CO was derived as the product of SV and heart rate (HR), where HR was calculated from the appropriate cardiac interval. Total peripheral resistance (TPR) was calculated as mean BP (MBP) divided by $\mathrm{CO}$, where MBP was calculated as the result of $\mathrm{DBP}+1 / 3$ (SBP-DBP). All values are reported as mean $\pm \mathrm{SD}$. Statistical analysis was performed by two-way ANOVA for repeated measures with time and treatment of sugar-type (glucose, galactose, fructose) as within-subject factors using statistical software (Statistix version 8.0; Analytical Software, St. Paul, MN). Where significant differences were found, the effects of each drink over time were analysed by comparing values at each time point over the post-drink period with the basal values recorded before drinking. One-way ANOVA with Dunnett's multiple comparison test and repeated-measures ANOVA with NewmanKeuls post hoc testing were used to test for changes over time from baseline level and to compare mean changes between the drink types. All reported $p$ values are twosided. For all tests, significance was set at $p \leq 0.05$.

\section{Sample size}

Our sample size is based on the results of our previous study [16], comparing BP responses to glucose and fructose. Assumptions are (1) a clinically relevant difference of $5 \mathrm{mmHg}$ between galactose and fructose in healthy subjects (averaged response over $120 \mathrm{~min}$ post-drink) and (2) a standard deviation of the difference in post-drink BP response of $5 \mathrm{mmHg}$. Therefore, using a type I error $(\alpha)$ of 0.05 and a desired power $(1-\beta)$ of 0.80 , such an investigation of repeated measures (on the same subject) would require a total number of 8 subjects.

\section{Results}

\section{Blood pressure}

For all cardiovascular parameters assessed, there were no significant differences in the baseline values across days (Table 1).

The BP responses to the sugary drinks are shown in Fig. 1 (panels a-c). In response to all three sugary drinks, SBP increased gradually to reach a plateau within an hour, and the significantly higher SBP values were maintained until the end of the study, i.e. 120 min post-drink. ANOVA indicates a significant effect of sugar-type $(p<0.05)$, with the increase in SBP in response to fructose $(7-8 \mathrm{mmHg}$ ) being greater than after glucose $(4-5 \mathrm{mmHg})$ or galactose $(2-3 \mathrm{mmHg})$. A significant effect of sugar-type has also been found in the DBP response $(p<0.05)$. As shown in Fig. 1 (panel b), DBP was also found to be increased to a greater extent with fructose, reaching a plateau of $\sim 5 \mathrm{mmHg}$ relative to baseline $(p<0.05)$, compared to
Table 1 Baseline

haemodynamic data before ingestion of the sugary drinks, each ingested as $500 \mathrm{~mL}$ of distilled water containing $60 \mathrm{~g}$ glucose, galactose or fructose

\begin{tabular}{lcccc}
\hline Sugary drink & Glucose & Galactose & Fructose & $p$ value \\
\hline Systolic blood pressure $(\mathrm{mmHg})$ & $122.2 \pm 8.9$ & $121.1 \pm 11.5$ & $121.0 \pm 10.2$ & 0.843 \\
Diastolic blood pressure $(\mathrm{mmHg})$ & $76.9 \pm 6.9$ & $75.1 \pm 8.4$ & $76.7 \pm 8.2$ & 0.541 \\
Heart rate, beats $\left(\mathrm{min}^{-1}\right)$ & $58.4 \pm 9.3$ & $61.5 \pm 11.1$ & $60.9 \pm 9.5$ & 0.294 \\
Stroke volume $(\mathrm{mL})$ & $91.1 \pm 15.7$ & $94.2 \pm 23.8$ & $90.0 \pm 20.8$ & 0.588 \\
Cardiac output $\left(\mathrm{L} \mathrm{min}^{-1}\right)$ & $5.3 \pm 0.8$ & $5.6 \pm 0.7$ & $5.4 \pm 1.0$ & 0.124 \\
Total peripheral resistance $\left(\mathrm{mmHg} \mathrm{L}^{-1} \mathrm{~min}\right)$ & $17.8 \pm 2.3$ & $16.3 \pm 2.1$ & $17.5 \pm 3.1$ & 0.098 \\
\hline
\end{tabular}

All data are presented as mean \pm SD. Baseline haemodynamic parameters for glucose, galactose and fructose were compared using one-way ANOVA 
A
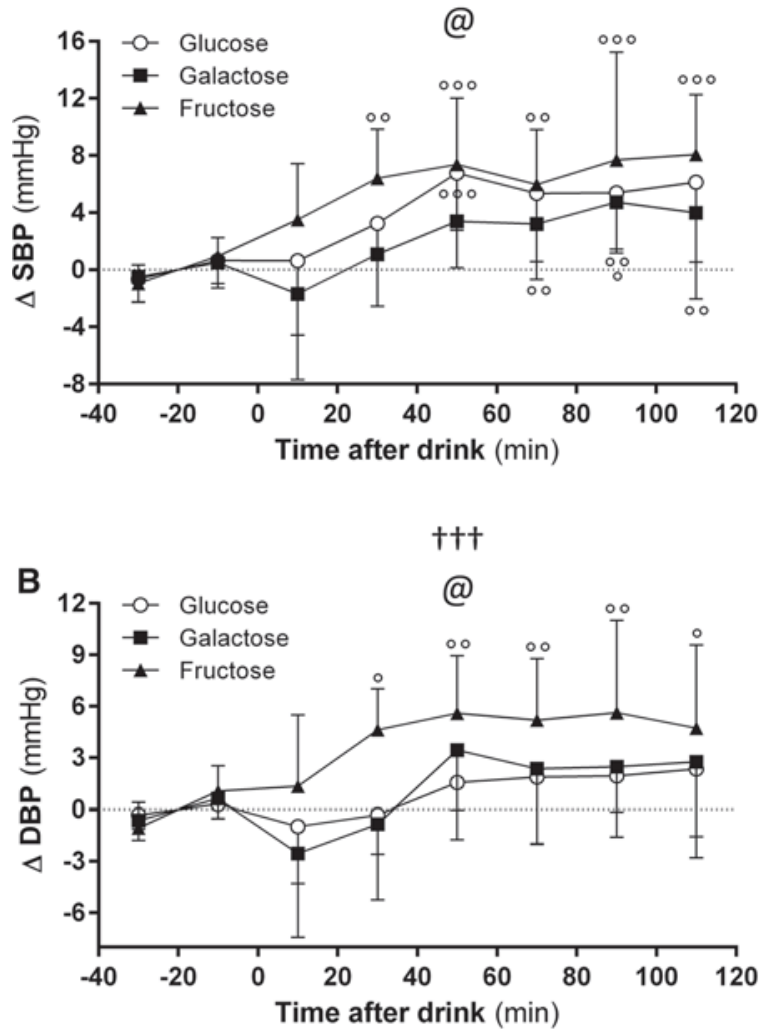

十七+

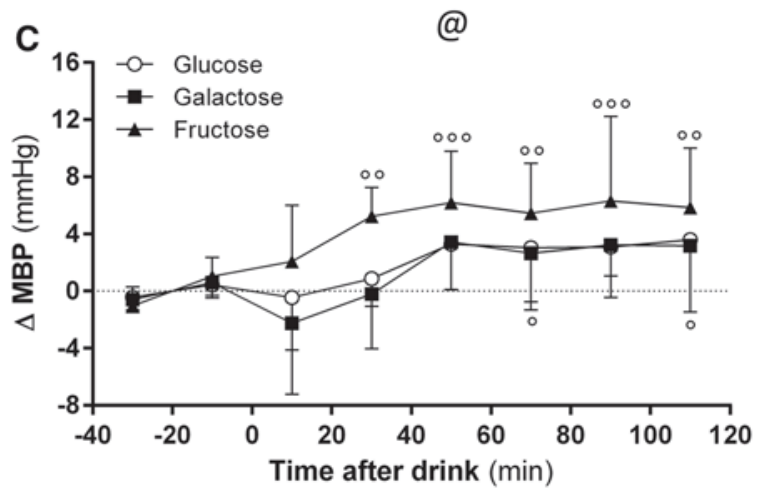

Fig. 1 Time course of changes in systolic blood pressure (SBP) a, diastolic blood pressure (DBP) b and mean blood pressure (MBP) (C) before and after ingestion of glucose (open circle), galactose (closed square) and fructose (closed triangle). Repeated-measures ANOVA assessed statistical differences as follows: effect of time (symbol dagger), effect of Sugar-type (symbol @) and the Sugartype $\times$ time interaction (symbol double dagger); one, two and three

non-significant increases of only $2-3 \mathrm{mmHg}$ in response to glucose or galactose. These more pronounced increases in SBP and DBP in response to fructose than to glucose or galactose are reflected in MBP (Fig. 1, panel c), which
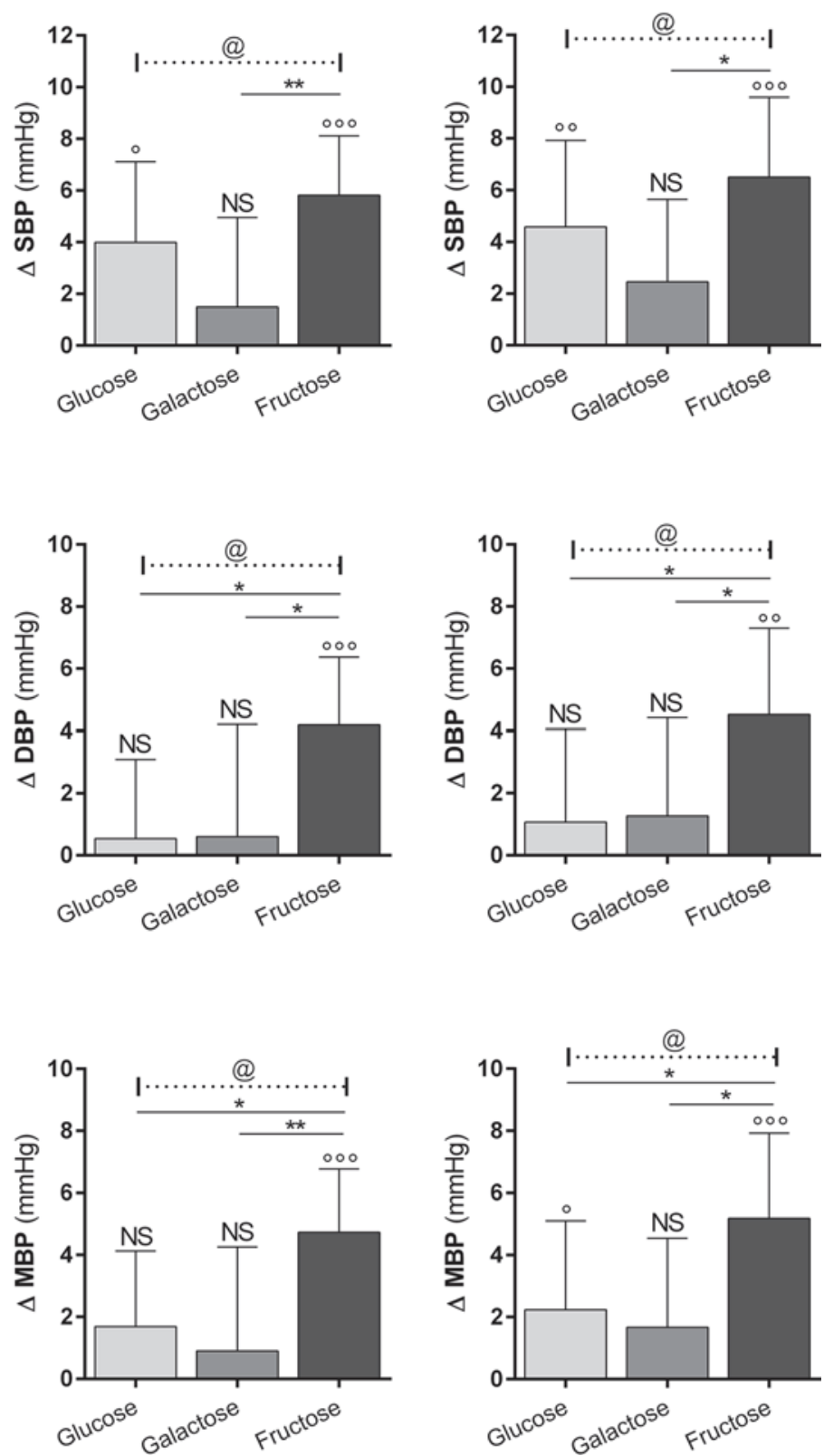

symbols denoting $p<0.05, p<0.01$ and $p<0.001$, respectively. For data on post-drink changes averaged over 60 and $120 \mathrm{~min}$ (shown as bars), post hoc pair-wise comparison for statistical differences across sugar-types is assessed by Dunnett's multiple comparison tests and indicated as follows: $* p<0.05,{ }^{*} p<0.01$ and ${ }^{* * *} p<0.001$. Significant difference between post-drink and baseline values are indicated as follows: NS non-significant; ${ }^{\circ} p<0.05,{ }^{\circ} p<0.01$ and ${ }^{\circ \circ} p<0.001$

showed, in the plateau phase, increases of about $6 \mathrm{mmHg}$ for fructose compared to only a $3 \mathrm{mmHg}$ increase for glucose or galactose (ANOVA: $p<0.05$ ). Pair-wise comparisons across the sugars for the average increases in BP over 
the $120 \mathrm{~min}$ (or first $60 \mathrm{~min}$ ) post-drink indicate that SBP, DBP and MBP are all significantly different between fructose versus glucose or between fructose versus galactose, but not between glucose versus galactose.

\section{Heart rate and stroke volume}

While all sugars increased HR reaching plateau values between 60 and 90 min post-drink (Fig. 2, panel a), a significant interaction effect of sugar-type and time (ANOVA, $p<0.001)$ is observed, with fructose ingestion resulting in the greatest elevation in HR $(+7 \mathrm{bpm})$ in the second hour post-drink compared to glucose $(+4-5 \mathrm{bpm})$ or galactose (+2-3 bpm). In contrast, fructose ingestion, like galactose ingestion, did not significantly increase SV (Fig. 2, panel b), while glucose increased SV with peak values (+8-12 $\mathrm{mL}$ ) between 15 and $45 \mathrm{~min}$ post-drink; the effect of sugar-type for SV is statistically significant, particularly during the first hour post-drink $(p<0.01)$.

\section{Cardiac output and total peripheral resistance}

The increase in BP in response to the fructose drink was accompanied by a modest increase in $\mathrm{CO}$ (Fig. 2, panel c) which reached a plateau after $45 \min (\Delta=0.5 \mathrm{~L} / \mathrm{min})$, but with no change in TPR (Fig. 2, panel d). This contrasts with the response to glucose, showing a significantly greater increase in $\mathrm{CO}$, particularly during the first $60 \mathrm{~min}$ postdrink $(\Delta=0.80-1.0 \mathrm{~L} / \mathrm{min})$, but also a significant decrease in TPR over that same time period before returning gradually towards baseline levels. In response to galactose, $\mathrm{CO}$ also increased, albeit to a much lesser extent than after glucose, reaching a plateau which was maintained between 30 and 90 min post-drink ( $\Delta \sim 0.35 \mathrm{~L} / \mathrm{min})$, and this plateau value after galactose tended to be lower and less sustained than that for fructose. This was accompanied by a small decline in TPR during 15-30 min post-drink before a return to baseline levels; this decline in TPR being much less pronounced than with glucose.

\section{Discussion}

This study compared acute cardiovascular responses of three dietary monosaccharides, galactose, glucose and fructose, in a randomized cross-over design. Our results confirm the greater impact of fructose than glucose on BP and also demonstrate that the BP-elevating effect of fructose is not mimicked by galactose ingestion. Furthermore, we show here that the increase in CO, as well as the decrease in TPR in response to glucose, is much less pronounced if compared to galactose ingestion. Galactose therefore combines the advantages of a low-glycemic index sugar with mild cardiovascular effects compared to fructose or glucose.

To our knowledge, only one study has previously examined acute BP responses to galactose in comparison with glucose and fructose. It was reported that SBP was not altered after galactose or fructose, but transiently increased (1-2 h) after glucose and that DBP was not altered by any of these three sugars [13]. The interpretation of this study's data is, however, limited for several reasons: (1) a higher baseline value was observed for fructose $(118-121 \mathrm{mmHg}$ ) than for glucose and galactose (111-114 mm Hg), which could hence contribute to the inability to demonstrate an increase in BP after fructose ingestion, (2) all of their subjects experienced watery diarrhoea after ingestion of fructose $(1 \mathrm{~g} / \mathrm{kg})$, most of them within $40-60$ min post-drink, (3) the consumption of a large distilled water preload ( $>1 \mathrm{~L}$ ) $2 \mathrm{~h}$ before the sugary drinks may also be an interfering factor in the cardiovascular responses after the sugary drinks and (4) BP was monitored by discontinuous oscillometric method and measured only once every hour. In the current study, in which we performed continuous beat-by-beat measurement of BP in response to the sugary drinks, we are able to confirm the BP-elevating effects of fructose observed in two previous studies in our laboratory using a similar experimental protocol and sugar load (60 g in $0.5 \mathrm{~L}$ water) $[16,17]$, namely a greater and sustained increase over at least $90 \mathrm{~min}$ in both SBP and DBP after fructose than after glucose ingestion. In these latter studies, glucose led to marginal or no increase in BP similar to that observed in the present studies after glucose and galactose. Moreover, based upon our previous observations $[16,21]$ that SBP tended to increase by a few $\mathrm{mmHg}$ over 1-2 $\mathrm{h}$ after a $0.5 \mathrm{~L}$ water load, our findings here of a small gradual increase in BP after glucose or galactose ingestion could be largely attributed to the water-load component of the sugar drinks rather than an effect of these sugars per se. Overall, in previous studies from our laboratory [16, 17] and in the present study, the BP response to fructose was found to be significantly greater than that after glucose by 3-4 mmHg. Furthermore, no differences are observed here between galactose and glucose in BP, whether SBP, DBP or MBP, and unexpectedly the ingestion of galactose, compared to glucose ingestion, resulted in a lesser effect with marginal impact on $\mathrm{HR}, \mathrm{SV}$ and $\mathrm{CO}$.

According to classic theory linking diet to BP regulation [19], the presence of macronutrients (particularly carbohydrates) in the diet would lead to increased circulating insulin levels, which can act centrally to stimulate sympathetic 

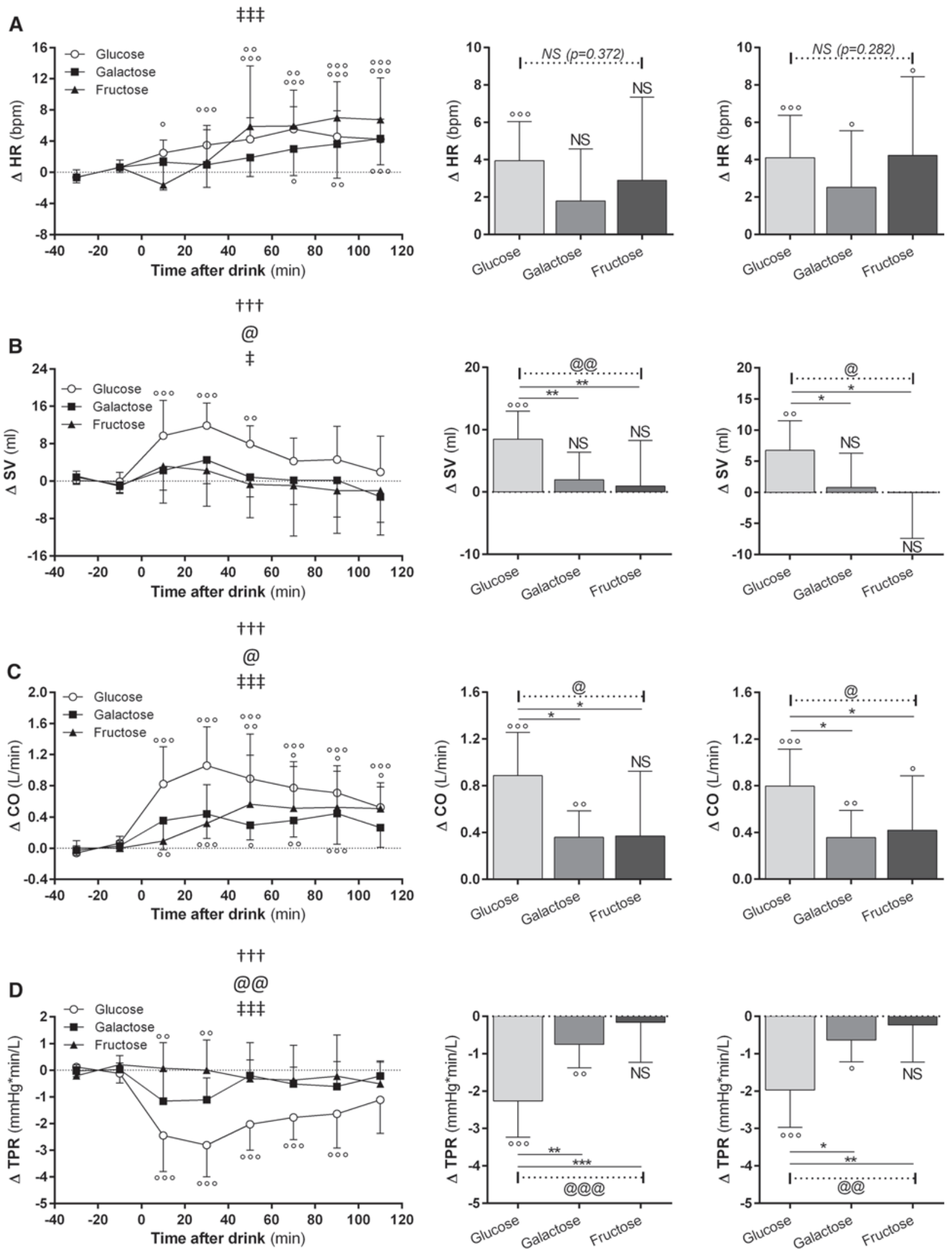
4Fig. 2 Time course for changes of heart rate (HR) (A), stroke volume (SV) (B), cardiac output $(\mathrm{CO})(\mathrm{C})$ and total peripheral resistance (TPR) (D), before and after ingestion of glucose (open circle), galactose (closed square) and fructose (closed triangle). Repeatedmeasures ANOVA assessed statistical differences as follows: effect of time (symbol dagger), effect of sugar-type (symbol @) and the sugartype $\times$ time interaction (symbol double dagger); one, two and three symbols denoting $p<0.05, p<0.01$ and $p<0.001$, respectively. For data on post-drink changes averaged over 60 and 120 min (shown as bars), post hoc pair-wise comparison for statistical differences across sugar-types is assessed by Dunnett's multiple comparison tests and indicated as follows: $* p<0.05, * * p<0.01$ and $* * * p<0.001$. Significant difference between post-drink and baseline values are indicated as follows: NS non-significant; ${ }^{\circ} p<0.05$; ${ }^{\circ} p<0.01$; and $\left.{ }^{\circ \circ} p<0.001\right)$

neural activity to the heart resulting in increased HR and $\mathrm{CO}$. However, as insulin also possesses potent vasodilatory properties in skeletal muscle micro- and macro-vasculature
[20], which are believed to contribute importantly to glucose clearance by this tissue, the resulting insulin-induced decrease in TPR would largely compensate for its central sympathetic stimulatory effects on the heart, thereby resulting in marginal or no increase in BP. The contrasting vascular responses to fructose and glucose ingestion might therefore be explained, at least in part, by the haemodynamic actions of insulin. Whether, in our present study, the decrease in TPR observed after galactose, albeit much less pronounced than after glucose, involves peripheral vasodilators distinct from insulin remains an intriguing question.

Our study has a number of limitations. First, we did not take venous blood samples in order to assess insulin and glucose values because the cannulation process could influence the subtle haemodynamic changes that are being monitored [25]. However, as summarized in Table 2, several past studies comparing postprandial glucose and

Table 2 Summary of studies reporting plasma insulin and glucose before and after ingestion of a sugary drink

\begin{tabular}{|c|c|c|c|c|c|c|c|}
\hline Study & Sugar-type & Subjects & Drink & $\begin{array}{l}\text { Baseline insulin } \\
(\mu \mathrm{U} / \mathrm{mL})\end{array}$ & $\begin{array}{l}\text { Baseline glucose } \\
(\mathrm{mmol} / \mathrm{l})\end{array}$ & $\begin{array}{l}\Delta \text { Insulin } \\
(\mu \mathrm{U} / \mathrm{mL})\end{array}$ & $\begin{array}{l}\Delta \text { Glucose } \\
(\mathrm{mmol} / \mathrm{L})\end{array}$ \\
\hline Blaak [26] & $\begin{array}{l}\text { Glucose }(75 \mathrm{~g}) \\
\text { Fructose }(75 \mathrm{~g})\end{array}$ & 10 men & $\begin{array}{l}400 \mathrm{~mL} \text { lemon } \\
\text { flavoured } \\
\text { water }\end{array}$ & $\begin{array}{l}9 \\
9\end{array}$ & $\begin{array}{l}4.8 \\
4.8\end{array}$ & $\begin{array}{l}44 \\
7\end{array}$ & $\begin{array}{l}1.3 \\
0.1\end{array}$ \\
\hline Rebello [13] & $\begin{array}{l}\text { Glucose }(1 \mathrm{~g} / \mathrm{kg} \mathrm{BW}) \\
\text { Fructose }(1 \mathrm{~g} / \mathrm{kg} \mathrm{BW}) \\
\text { Galactose }(1 \mathrm{~g} / \mathrm{kg} \mathrm{BW})\end{array}$ & 20 women & $\begin{array}{l}20 \mathrm{~mL} \text { water } \\
\text { per kg BW }\end{array}$ & $\begin{array}{l}22 \\
29 \\
24\end{array}$ & $\begin{array}{l}4.4 \\
4.4 \\
4.5\end{array}$ & $\begin{array}{l}73 \\
7 \\
8\end{array}$ & $\begin{array}{l}1.7 \\
0.2 \\
0.0\end{array}$ \\
\hline Fukagawa [27] & $\begin{array}{l}\text { Glucose }(75 \mathrm{~g}) \\
\text { Fructose }(75 \mathrm{~g})\end{array}$ & $\begin{array}{r}6 \text { men-2 } \\
\text { women }\end{array}$ & $\begin{array}{l}500 \mathrm{~mL} \text { lemon } \\
\text { flavoured } \\
\text { water }\end{array}$ & $\begin{array}{l}5 \\
5\end{array}$ & $\begin{array}{l}4.4 \\
4.4\end{array}$ & $\begin{array}{l}60 \\
12\end{array}$ & $\begin{array}{l}3.2 \\
0.9\end{array}$ \\
\hline Münstedt [28] & $\begin{array}{l}\text { Glucose }(75 \mathrm{~g}) \\
\text { Fructose }(75 \mathrm{~g})\end{array}$ & 15 men & $\begin{array}{l}\text { Total volume of } \\
300 \mathrm{~mL}\end{array}$ & $\begin{array}{l}4.5 \\
6.5\end{array}$ & $\begin{array}{l}5.1 \\
4.1\end{array}$ & $\begin{array}{l}45 \\
10\end{array}$ & $\begin{array}{l}1.0 \\
0.7\end{array}$ \\
\hline Schwarz [29] & $\begin{array}{l}\text { Glucose }(75 \mathrm{~g}) \\
\text { Fructose }(75 \mathrm{~g})\end{array}$ & $\begin{array}{l}10 \text { men-10 } \\
\text { women }\end{array}$ & $\begin{array}{l}\text { Total volume of } \\
200-300 \mathrm{~mL}\end{array}$ & $\begin{array}{l}12 \\
12\end{array}$ & $\begin{array}{l}4.8 \\
4.8\end{array}$ & $\begin{array}{l}95 \\
22\end{array}$ & $\begin{array}{l}2.6 \\
0.4\end{array}$ \\
\hline Tappy [30] & $\begin{array}{l}\text { Glucose }(75 \mathrm{~g}) \\
\text { Fructose }(75 \mathrm{~g})\end{array}$ & 10 & $\begin{array}{l}\text { Total volume of } \\
300 \mathrm{~mL}\end{array}$ & $\begin{array}{l}8 \\
8\end{array}$ & $\begin{array}{l}5.1 \\
5.1\end{array}$ & $\begin{array}{l}50 \\
10\end{array}$ & $\begin{array}{l}3.8 \\
0.9\end{array}$ \\
\hline Ganda (12) & $\begin{array}{l}\text { Glucose }(50 \mathrm{~g}) \\
\text { Galactose }(50 \mathrm{~g}) \\
\text { Fructose }(50 \mathrm{~g})\end{array}$ & 10 men & $\begin{array}{l}\text { Total volume of } \\
150 \mathrm{~mL}\end{array}$ & $\begin{array}{l}7.5 \\
7.5 \\
9.0\end{array}$ & $\begin{array}{l}4.2 \\
4.4 \\
4.4\end{array}$ & $\begin{array}{l}51 \\
20 \\
13\end{array}$ & $\begin{array}{l}2.9 \\
0.6 \\
0.4\end{array}$ \\
\hline Williams [31] & $\begin{array}{l}\mathrm{Gal} \mathrm{A}(0.5 \mathrm{~g} / \mathrm{kg}, n=11) \\
\mathrm{Gal} \mathrm{B}(0.5 \mathrm{~g} / \mathrm{kg}, n=11) \\
\mathrm{Gal} \mathrm{C}(0.5 \mathrm{~g} / \mathrm{kg}, n=6)\end{array}$ & $\begin{array}{c}20 \text { men-11 } \\
\text { women }\end{array}$ & $\begin{array}{l}\text { Sugars dis- } \\
\text { solved in } \\
4 \mathrm{~mL} \text { of water } \\
\text { per kg BW }\end{array}$ & $\begin{array}{l}7 \\
10 \\
8\end{array}$ & $\begin{array}{l}4.1 \\
4.4 \\
4.6\end{array}$ & $\begin{array}{l}12.3 \\
6 \\
7.8\end{array}$ & $\begin{array}{l}0.2 \\
0.3 \\
0.2\end{array}$ \\
\hline Coss-Bu [14] & $\begin{array}{l}\text { Galactose }(\sim 50 \mathrm{~g}) \\
\text { Fructose }(\sim 45 \mathrm{~g})\end{array}$ & $\begin{array}{l}3 \text { men-3 } \\
\text { women }\end{array}$ & $\begin{array}{c}\text { Prior infusion } \\
\text { of } \sim 120 \mathrm{mg} \\
\text { Glc in } 8 \mathrm{~h} \\
\text { Water added? }\end{array}$ & $\begin{array}{l}5.3 \\
7.1\end{array}$ & $\begin{array}{l}4.8 \\
4.4\end{array}$ & $\begin{array}{l}9.0 \\
11.2\end{array}$ & $\begin{array}{l}0.4 \\
0.4\end{array}$ \\
\hline $\begin{array}{l}\text { Sunehag and } \\
\text { Hamond [15] }\end{array}$ & $\begin{array}{l}\text { Galactose } \\
\left(11 \mu \mathrm{mol} \mathrm{kg} \mathrm{kg}^{-1} \mathrm{~min}^{-1}\right) \\
\text { Galactose plus glucose } \\
\left(11 \mu \mathrm{mol} \mathrm{kg} \mathrm{kin}^{-1} \text {, }\right. \\
\text { respectively) }\end{array}$ & 5 females & $\begin{array}{l}\text { Ingestion over } \\
120 \mathrm{~min}\end{array}$ & $\begin{array}{l}3.7 \\
5.0\end{array}$ & $\begin{array}{l}4.7 \\
5.0\end{array}$ & $\begin{array}{l}3.2 \\
9.3\end{array}$ & $\begin{array}{l}0.3 \\
0.6\end{array}$ \\
\hline
\end{tabular}

Glc glucose. Values for plasma insulin and glucose levels were either obtained from tables or estimated from figures. A conversion factor of 0.555 was used to convert $\mathrm{mg} / \mathrm{dL}$ to $\mathrm{mmol} / \mathrm{L}$ in the study by Williams et al. [31]. Data from the study by Ganda et al. [12] have been reported for not more than 30 min post-drink 
insulin responses to these monosaccharides (in amounts similar to those used in our study here) have consistently shown markedly lower rise in circulating glucose and insulin following fructose and galactose than after glucose [12-15, 26-31]. Second, our study was conducted only in men. In this first "proof-of-concept" study about the cardiovascular impact of galactose, we focused on men because including women would have increased substantially the number of subjects and testing days (cross-over design) in order to observe a potential gender effect with sufficient statistical power. Third, based on our selective study population, which included only young and healthy men of normal body weight, our findings cannot be extrapolated to the general population. Further studies are warranted to explore the proof-of-concept presented here of a favourable haemodynamic profile of galactose (besides its lowglycemic index) in patients with cardiac insufficiency and impaired glucose metabolism (i.e. impaired glucose tolerant patients and/or type 2 diabetic patients).

In conclusion, this study demonstrates that galactose resembles glucose in its marginal impact on BP, which contrasts with the significant BP-elevating effect of fructose ingestion. Furthermore, it has a much less pronounced effect on cardiac workload than glucose. Galactose thus presents the interesting characteristics of a low-glycemic sugar with mild cardiovascular effects. Further studies are warranted to confirm the clinical relevance of the milder cardiovascular effects of galactose compared to other sugars for insulin resistant obese and/or diabetic patients with cardiac insufficiency and also to investigate whether this beneficial cardiac effect of galactose would persist when consumed together with other monosaccharides (i.e. glucose, fructose or sucrose), as well as when integrated in meals in more chronic studies.

Acknowledgments Research related to this paper was funded in part by the Swiss National Science Foundation and in part by intramural funding.

\section{Compliance with ethical standards}

Conflict of interest The authors declare that they have no conflict of interest.

\section{References}

1. Bray GA, Nielsen SJ, Popkin BM (2004) Consumption of highfructose corn syrup in beverages may play a role in the epidemic of obesity. Am J Clin Nutr 79(4):537-543

2. Tappy L, Le KA, Tran C et al (2010) Fructose and metabolic diseases: new findings, new questions. Nutrition 26(11-12):1044-1049

3. Adam TC, Westerterp-Plantenga MS (2005) Nutrient-stimulated GLP-1 release in normal-weight men and women. Horm Metab Res 37(2):111-117
4. Adam TC, Westerterp-Plantenga MS (2005) Glucagon-like peptide-1 release and satiety after a nutrient challenge in normalweight and obese subjects. Br J Nutr 93(6):845-851

5. Burelle Y, Lamoureux MC, Peronnet F et al (2006) Comparison of exogenous glucose, fructose and galactose oxidation during exercise using 13C-labelling. Br J Nutr 96(1):56-61

6. Mohammad MA, Sunehag AL, Rodriguez LA et al (2011) Galactose promotes fat mobilization in obese lactating and nonlactating women. Am J Clin Nutr 93(2):374-381

7. Sclafani A, Ackroff K (2012) Flavor preferences conditioned by intragastric glucose but not fructose or galactose in C57BL/6J mice. Physiol Behav 106(4):457-461

8. O'Hara JP, Carroll S, Cooke CB et al (2012) Preexercise galactose and glucose ingestion on fuel use during exercise. Med Sci Sports Exerc 44(10):1958-1967

9. Duckworth LC, Backhouse SH, Stevenson EJ (2013) The effect of galactose ingestion on affect and perceived exertion in recreationally active females. Appetite 71:252-258

10. Duckworth LC, Backhouse SH, O'Hara JP et al (2016) Effect of galactose ingestion before and during exercise on substrate oxidation, postexercise satiety, and subsequent energy intake in females. J Am Coll Nutr 35(1):1-12

11. Mayes PA (1993) Intermediary metabolism of fructose. Am J Clin Nutr 58:754S-765S

12. Ganda OP, Soeldner JS, Gleason RE et al (1979) Metabolic effects of glucose, mannose, galactose, and fructose in man. J Clin Endocrinol Metab 49(4):616-622

13. Rebello T, Hodges RE, Smith JL (1983) Short-term effects of various sugars on antinatriuresis and blood pressure changes in normotensive young men. Am J Clin Nutr 38(1):84-94

14. Coss-Bu JA, Sunehag AL, Haymond MW (2009) Contribution of galactose and fructose to glucose homeostasis. Metabolism 58(8):1050-1058

15. Sunehag AL, Haymond MW (2002) Splanchnic galactose extraction is regulated by coningestion of glucose in humans. Metabolism 51:827-832

16. Brown CM, Dulloo AG, Yepuri G et al (2008) Fructose ingestion acutely elevates blood pressure in healthy young humans. Am J Physiol Regul Integr Comp Physiol 294(3):R730-R737

17. Grasser EK, Dulloo A, Montani JP (2014) Cardiovascular responses to the ingestion of sugary drinks using a randomised cross-over study design: does glucose attenuate the blood pressure-elevating effect of fructose? Br J Nutr 112(2):183-192

18. Visvanathan R, Chen R, Garcia M et al (2005) The effects of drinks made from simple sugars on blood pressure in healthy older people. Br J Nutr 93(5):575-579

19. Landsberg L, Young JB (1985) Insulin-mediated glucose metabolism in the relationship between dietary intake and sympathetic nervous system activity. Int J Obes 9:63-68

20. de Jongh RT, Clark AD, IJzerman RG et al (2004) Physiological hyperinsulinaemia increases intramuscular microvascular reactive hyperaemia and vasomotion in healthy volunteers. Diabetologia 47(6):978-986

21. Girona M, Grasser EK, Dulloo AG et al (2014) Cardiovascular and metabolic responses to tap water ingestion in young humans: does the water temperature matter? Acta Physiol (Oxf) 211(2):358-370

22. Grasser EK, Goswami N, Hinghofer-Szalkay H (2009) Presyncopal cardiac contractility and autonomic activity in young healthy males. Physiol Res 58(6):817-826

23. Kubicek WG, Patterson RP, Witsoe DA (1970) Impedance cardiography as a non-invasive method of monitoring cardiac function and other parameters of the cardiovascular system. Ann NY Acad Sci 170:724-732

24. Fortin J, Habenbacher W, Heller A et al (2006) Non-invasive beat-to-beat cardiac output monitoring by an improved method 
of transthoracic bioimpedance measurement. Comput Biol Med 36(11):1185-1203

25. Langham BT, Harrison DA (1993) The pressor response to venous cannulation: attenuation by prior infiltration with local anaesthetic. Br J Anaesth 70(5):519-521

26. Blaak EE, Saris WH (1996) Postprandial thermogenesis and substrate utilization after ingestion of different dietary carbohydrates. Metabolism 10:1235-1242

27. Fukagawa NK, Veirs H, Langeloh G (1995) Acute effects of fructose and glucose ingestion with and without caffeine in young and old humans. Metabolism 44:630-638

28. Münstedt K, Böhme M, Hauenschild A et al (2011) Consumption of rapeseed honey leads to higher serum fructose levels compared with analogue glucose/fructose solutions. Eur J Clin Nutr 65:77-80

29. Schwarz JM, Schutz Y, Froidevaux F et al (1989) Thermogenesis in men and women induced by fructose vs glucose added to a meal. Am J Clin Nutr 49:667-674

30. Tappy L, Randin JP, Felber JP et al (1986) Comparison of thermogenic effect of fructose and glucose in normal humans. Am J Physiol Endocrinol Metab 13:718-724

31. Williams CA, Phillips T, Macdonald I (1983) The influence of glucose on serum galactose levels in man. Metabolism 32(3):250-256 